\title{
The Syntactic Relationship Between Transitivity and Voice
}

\author{
Roseline Abonego Adejare \\ Department of Language, Arts and Social Science Education, Lagos State University, Ojo, Lagos, Nigeria
}

\section{Email address:}

abonego@yahoo.com

\section{To cite this article:}

Roseline Abonego Adejare. The Syntactic Relationship Between Transitivity and Voice. International Journal of Language and Linguistics. Vol. 3, No. 2, 2015, pp. 40-51. doi: 10.11648/j.ij11.20150302.12

\begin{abstract}
This study presents a holistic description of the syntactic relationship between transitivity and voice, which has not attracted overt attention. The data comprises 2,187 finite verbal group (FVBG) clauses abstracted from a 17,600-word corpus of orthographically transcribed spoken instructional texts recorded in selected secondary schools in Lagos State, Nigeria. The scale-and-category version of the systemic grammatical model aided the analysis. Fourteen features of syntactic relationship were identified in the literature and their occurrence in the data was ascertained. The pattern and frequency of occurrence of transitivity and voice were determined. Findings confirm the fourteen features and show that the same 1,180 FVBG clauses indicated both transitivity and voice. Voice was however syntactically more basic than transitivity because its unmarked active voice was 26 per cent higher than transitivity's unmarked transitive. Transitivity was 67 per cent transitive and 33 per cent intransitive while voice was 91 per cent active and 9 per cent passive. Their joint occurrence was 65 per cent active transitive, 25 per cent active intransitive, 8.1 per cent passive intransitive, and 1 per cent passive transitive. Only rarely did there occur such perfect correspondences as active transitive with passive transitive. Passive intransitive clauses with animate subjects were restricted to the text dealing with persons and personalities. The transitive verbal group clause with the rankshifted clause as complement and the non-let imperative clause were shown to be passivisable without extraposition and replacement, and against traditionally held views on transitivity and voice, respectively.
\end{abstract}

Keywords: Transitivity, Transitive, Intransitive, Voice, Active, Passive, Finite Verbal Group Clause

\section{Introduction}

The term transitivity is traditionally used to classify verbs into two types according to whether or not they occur with a nominal complement. Those that occur with nominal complements are known as transitive verbs while those without complements are called intransitive verbs[1]. Many verbs are Janus-faced in this regard, admitting, and not admitting, complements[2], with some accepting two [3]. Of Latin origin, transitivity means "going across" or "passing over" the effects of the verbal action from the actor to the goal [4]. To be transitive or intransitive therefore implies "going through", or "not going through", with respect to the verbal action "extending" or not "extending to some other entity" [5]. For [6] transitivity originates from the "major" clause, "the clause containing a predication". Transitivity is thus "the representation in language of PROCESSES, the PARTICIPANTS therein and the CIRCUMSTANTIAL features associated with them"; it "refers to the experiential organisation of the clause"[7]. This makes transitivity a system of both the clause and the verbal group [2].
Reference [3] defines voice as "a grammatical category which makes it possible to view the action of a sentence in either of two ways, without change in the facts reported". It is the term used to distinguish an active verbal group from a passive one. There are thus two terms in the system of voice, active and passive: The passive is formed by adding a form of auxiliary $\mathrm{BE}$ to the $\mathrm{x}+\mathrm{n}$ past participle form of the active verb [8]. As [9] and [10] vividly describe it, the passive also requires a rearrangement of the elements of the clause structure, such that the nominal complement of the active voice verbal group becomes the subject of the passive, while that originally in subject position turns into a prepositional group introduced by the agent marker $b y$, and is moved to the optional adjunct position. Voice belongs both to the clause system and to the verbal group system[2]. As a system of the clause, it is associated with the semantic role of the subject as actor; and, as a system of the verbal group, it relates to the morphological variation of the verb occasioned by the reversal of the role of the subject. Reference [8] regards 
voice "as a grammatical system in the verbal group"(See also [11]), but handles its active and passive terms both at the rank of the finite verbal group(FVBG) and at the rank of the FVBG clause.

Transitivity and voice are thus systems of both the verbal group and the clause. This suggests a fundamental relationship between them: The transformational operation that changes an active voice clause into a passive one concomitantly results in a change in transitivity from transitive to intransitive. Moreover, they are related through the ergative system[12]. Because their functions and realisations invariably affect other elements of the clause structure, transitivity and voice are often seen as primarily systems of the clause and secondarily systems of the verbal group [2]. Proponents of Systemic Functional Grammar however ascribe transitivity to the clause alone [5].

\section{Background}

In [13] considerable attention was paid to the verbal group systems, including transitivity and voice, and some account of multiple systems convergence on the verbal group was made, but the possibility of a syntactic relationship holding between transitivity and voice was not explored. It was only noted in passing that a verbal group primarily marked for passive voice can also be intransitive. Yet there exists closer ties between transitivity and voice than that, as evident in the literature on both subjects. Take the following concessive remark [3], for example:

Although it is a general rule that transitive verb sentences can be either active or passive, there are a number of exceptions where the active (transitive) and passive sentences are not in systematic correspondence.

Three features of syntactic relationship are discernible from the above statement: A transitive verb can also be an active voice verb; a transitive verb can also be a passive voice verb; and, passivisation is not possible with some active transitive verbs.

Features of syntactic relationship such as these abound in the grammar, but they are only mentioned incidentally and are not known to have been studied in any systematic way. Describing the syntactic relationship between transitivity and voice would deepen our understanding of their patterning as separate systems of both the verbal group and the clause.

Against the foregoing background, this study presents a holistic description of the syntactic relationship between transitivity and voice: It (1) determines the pattern and frequency of occurrence of both systems, (2) identifies features of syntactic relationship in the literature and ascertains their occurrence in the data, and (3) accounts for possible variations against existing claims.

Following these preliminary remarks are a description of the research design, analysis of data, and conclusions in that order.

\section{Research Design}

A 17,600-word corpus of spoken instructional texts recorded in selected secondary schools in Lagos State, Nigeria form the data-base. The texts are Christian Religious Knowledge (R), Geography (G), Physics (P), and Chemistry (C) and the topics taught were respectively The Mission of the Church, Drainage System, Electric Field, and Nitrogen. The texts were orthographically transcribed, and the clauses and verbal groups therein were identified and numbered. The scale-and-category version of the systemic grammatical model [14], complemented with simple statistics, aided the analysis.

Existing literature was critically reviewed for possible syntactic relationship between transitivity and voice. Fourteen were identified as follows:

1. Transitive verbal group clauses can be either active or passive.

2. Transitivity and voice concern verbs and other constituents of the clause.

3. Passives derive from active transitive verbs.

4. Intransitive verbal groups are syntactically like passives.

5. Passive verbal groups are invariably intransitive.

6. Passivisation is only possible with transitive verbal groups.

7. Some ditransitive verbal group clauses yield dual passive constructions.

8. Particled idiomatic verbal groups must be followed by their nominal complements, if active.

9. Both transitive and active voice verbs occur with animate nominal group subjects.

10. Not all active transitive clauses have passive counterparts.

11. Transitive verbs with rankshifted clauses as complements are passivisable by extraposition and replacement only.

12. Some verbs occur only as passives and can therefore not be active or transitive.

13. Transitivity selects finite only, but the passive can be both finite and non-finite.

14. The transitive and intransitive occur only as predicators, but the passive appears unrestricted.

The texts were examined to abstract the FVBG clauses. These numbered 2,187 and they constitute the data. Each FVBG clause was critically examined to determine its status with respect to transitivity and voice (Imperative clauses and clauses with copular verbs were ignored). The FVBG clauses indicating transitivity and voice were then examined to ascertain their reflection of any, or all, of the fourteen features of syntactic relationship identified in the grammar. The pattern and frequency of occurrence of both transitivity and voice (and terms thereof) were also determined.

\section{Analysis of Data}

The analysis of data was in two parts, as already indicated 
above. Details are presented as follows.

\subsection{Frequency Distribution of Transitivity and Voice}

Out of the 2,187 FVBG clauses examined 1,180 indicated both transitivity and voice. Their distribution however differed markedly. There were 794 transitive and 386 intransitive FVBG clauses; in contrast, there occurred 1,074 active and 106 passive voice FVBG clauses. Thus active voice was 26 per cent more recurring than transitive, but intransitive verbal group clauses were three times more frequent than passive voice.

Of the 794 transitive FVBG clauses only 1.3 per cent (10) was passive transitive; the rest 99 per cent (784) was active transitive. Mono transitivity was dominant with 730 clauses (92 per cent): Only 64 (8 per cent) ditransitive clauses occurred and none was passive. The nominal group was dominant as complement (657 or 83 per cent), and it was significantly 38 per cent pronoun-headed; the rankshifted clause accounted for 17 per cent (134). The 386 intransitive FVBG clauses were 75 per cent (290) active intransitive and 25 per cent (96) passive intransitive. Those with adjuncts represent 59 per cent (229) while the adjunctless accounted for 41 per cent(157). The adjuncts were realised by the prepositional group (153 or 67 per cent), adverbial group (71 or 31 per cent) and nominal group ( 5 or 1.3 per cent); and, as the bracketed figures show, the prepositional group was the most frequent adjunct. No rankshifted clause occurred.

The 1,074 active voice FVBG clauses comprise 784 (73 per cent) active transitive and 290 ( 27 per cent) active intransitive, which makes the active transitive subtype dominant. In contrast, the 106 passive voice verbal group clauses were dominated by the passive intransitive (96 or 91 per cent), 40 per cent (38) of which was adjunctless. The passive transitive was rare, with 10 occurrences ( 10 per cent). Transitivity and voice occurrence was thus 65 per cent active transitive, 25 per cent active intransitive, 8.1 per cent passive intransitive, and 1 per cent passive transitive. These figures suggest that transitive verbal group clauses are predominantly active verbal group clauses and that, while intransitive verbal group clauses occur far more as active than passive, passive voice clauses are essentially intransitive. They are also proofs of the syntactic relationship between transitivity and voice.

\subsection{Features of Syntactic Relationship between Transitivity and Voice}

This section presents the fourteen features of syntactic relationship between transitivity and voice identified in the literature. Items 1-8 show similarities while 9-14 point to differences. Each feature is accorded a separate heading. Existing claims are stated, followed by remarks on their occurrence in the data. Excerpts illustrating each feature are analysed, except where no insights are to be gained. Each is preceded by the source text's code, the letter K (for clause), and the clause's number. The verbal group concerned is italicised, with its number enclosed in brackets. Placed in front of some excerpts are the abbreviations AT for active transitive, AI for active intransitive, PT for passive transitive, and PI for passive intransitive.

\subsubsection{Transitive Verbal Group Clauses can Be either Active or Passive}

The general rule that transitive verbal group clauses can be either active or passive [3] was confirmed, as the following excerpts show.

(1d) CK538 || They| separate (582) | the components of air.||(AT)

The rarity of the passive transitive verbal group clause noted above might find explanation in the tendency of passives to function at the most delicate level syntactically. An example is marked in (1ei) and analysed as (1eii) below.

(1ei) RK37a||| ( $\beta$ ) Because $\mid$ he $\mid$ died |from his faith, $\|$ K38 $\|$ that |'s | [[why he was called (49) a martyr]]. $\|$

$$
\begin{gathered}
\text { A } \\
\text { (1eii) } \| \text { why } \mid \text { he } \mid \text { was called (49) } \mid \text { a martyr. } \|(\mathrm{PT})
\end{gathered}
$$

Another shared syntactic similarity between transitivity and voice relates to copular verbs, which are neither active transitive nor passivisable [3].

(1fi) RK74 He was (93) one of the seven Christians that was chosen.

(1fii) GK520 So the river that has characteristic features of maturity is now having a youthful, exuberant phase. K421 It has become (570) younger.

\subsubsection{Transitivity and Voice Concern Verbs and other Constituents of the Clause}

Since transitivity and voice are clausal systems as well as verbal group systems, it follows that their operations would involve all elements of the clause structure [3], namely the subject, predicator, complement, and adjunct. This is illustrated below. 
S P C

(2a) RK131|| They $\mid$ saw (164) | the signs [[ performed by Philip]].||(AT)

$\mathrm{S} \quad \mathrm{P}$ A

(2b) GK530 || The river | moves (576) | sluggishly.||(AI)

A $\mathrm{S} \quad \mathrm{P}$

K532 || Now | materials | are being deposited (577).||(PI)

$+\mathrm{S} \quad \mathrm{P}$

(2c) PK556 || And |we | are being asked to find (618) | the resultant electric field intensity.||(PT)

$\mathrm{S} \quad \mathrm{P} \quad \mathrm{C} \quad \mathrm{A}$

(2d) CK548 || You | pass (594) | the air| into this thing.||...(AT)

$\mathrm{S} \quad \mathrm{P} \quad \mathrm{A}$

K558 || It| 's passed (602) | through lime water.|(PI)

\subsubsection{Passives Derive from Active Transitive Verbs}

It is given that passives derive from active transitive verbal groups[15]. However, only rarely did there occur such perfect correspondences as [16]'s "John opened the letter" and "The letter was opened by John". The active transitive counterpart of (2c) is analysed as (3a) while another set is shown in (3b) below.

$$
+\mathrm{S} \quad \mathrm{P} \quad \mathrm{C}_{1} \quad \mathrm{C}_{2}
$$

(3a) PK612|| But | the question | asks (671) | you| [[ to find the resultant electric field intensity]].\| (AT)

$$
\mathrm{S} P \mathrm{P}
$$

(3b) RK140 || He | demonstrated (183)| the power. $\mid \ldots$.. (AT

$$
\mathrm{S} \quad \mathrm{A} \quad \mathrm{P}
$$

$\mathrm{K} 142 \|(\alpha)$ the power | also | was demonstrated (185).|(PI)

Because they occurred largely in rankshifted clauses, passive constructions, such as that in (3c) below, can however not be said to derive directly from the active.
$\mathrm{A}_{1}$
$\mathrm{S}$
$\mathrm{C}$
$\mathrm{A}_{2}$

And

(3c) RK261 || And | immediately | they | rebuked | him | [[ because it is a gift that cannot be

$$
\text { purchased (339) with money]] ||.(PI) K262 || You | cannot buy (340) | it||...(AT) K316 }
$$
A
$\mathrm{S}$
$\mathrm{P}$
$\mathrm{C}$

|| So | the gift of the Holy Spirit | is not | something [[ that can be bought (414)]].||(PI)

There was, moreover, the issue of morphologically similar but lexically different verbs.

$$
\mathrm{S}
$$

$$
\mathrm{P}
$$

A

(3d) PK643a || The test charge | is being pulled (712) | towards the negative charge ||(PI)

$$
\mathrm{S} \quad \mathrm{P} \quad \mathrm{C} \text { A }
$$

and K643b || the positive charge | is pushing (713) | the test charge | towards the negative

charge. $\|$ (AT)... K665||...as | the negative | is pulling (736)| the test charge ||(AT)

The active transitive also occurred as rankshifted clauses. Thus, if the complement of K139 in (3ei) is syntactically understood as resulting from (3eii) below, it becomes clear that the passive transitive analysed as (1b) above is derived from (3eii).

(3ei) GK138 Then we are now seeing that a feature is now created and

$$
\begin{gathered}
\mathrm{S} \\
\mathrm{K} 139
\end{gathered}
$$

(3eii) $\mid$ We $\mid$ call $\mid$ that feature | a spur.||(AT)

Many passive intransitive clauses lack active transitive counterparts, but they are constructible from context, as illustrated below.

$$
\mathrm{S} \quad \mathrm{P} \quad \mathrm{A}
$$

(3fi) CK786||Which component of air | is removed (831)| by alkaline paragallol?||(PI)

$$
\mathrm{S} \quad \mathrm{P} \quad \mathrm{C}
$$

(3fii) ||Alkaline paragallol | removes | a component of air.||(AT)

A good number of the active transitive similarly lack passive transforms. Again, they are constructible. Thus ( $3 \mathrm{~g})$ below is the passive transitive analogue of (1c) above. 


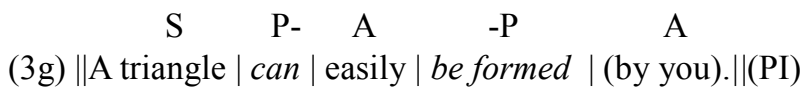

\subsubsection{Intransitive Verbal Groups Are Syntactically like Passives}

Intransitive verbal group clauses are like passives[9]. Since they occur with or without adjuncts, they syntactically resemble passives with expressed agents on the one hand, and agentless passives on the other hand. Compare intransitive verbal group clauses with adjuncts in (4ai) and (4aii), and passives with expressed agents in (4b), below.

$\begin{array}{ccc}\mathrm{S} & \mathrm{P} & \mathrm{A} \\ \text { (4ai) RK284 } \| \mathrm{He} & \text { prayed } & \text { (367) } \\ \mathrm{S} & \mathrm{P} & \mathrm{f}\end{array}$

(4aii) GK101|| It | moves (107) | freely.||

$$
\mathrm{S} \quad \mathrm{P} \quad \mathrm{A}
$$

(4b) CK606|| The oxygen | will be taken up (663)| by who?||

Adjunctless intransitive verbal group clauses are shown in (4ci) and (4cii), agentless passives in (4di) and (4dii), and agentless passive intransitive verbal groups with non-agentive adjuncts in (4ei) and (4eii), below.

$$
\begin{gathered}
\mathrm{S} \\
\text { (4ci) CK416 } \| \mathrm{We} \mid \underset{\mathrm{S}}{\text { compressed }} \text { (458). } \|_{\mathrm{P}}
\end{gathered}
$$

(4cii) PK501|| The decimal place | has shifted (541).||

$$
\text { A } \mathrm{S} \quad \mathrm{P}
$$

(4di) RK360 || Apart from healing the sick | demons | were cast out (463).||

$$
\begin{aligned}
& \begin{array}{llll}
\mathrm{S} & \mathrm{P} & + & \mathrm{P}
\end{array} \\
& \mathrm{S} \quad \mathrm{P} \quad \mathrm{A}
\end{aligned}
$$

(4ei) GK254|| Such a system | is known (296) | as abrasion process.||

$$
\mathrm{S} \quad \mathrm{P} \quad \mathrm{A}
$$

(4eii) PK618|| These triangles | are arranged (679) | on a straight line.||

Notice that, with the exception of (4ci), all the subjects indicate goal rather than actor, and that the active transitive analogue is recoverable from context. For instance, the active transitive counterpart of (4di) is Apart from healing the sick the Holy Spirit cast out demons of people. That cannot be said of (4cii) however, which, due to the unknowableness of the agent, cannot be transformed into the active transitive even by ergative means: Who/What shifted the decimal place? Granted that it is mathematically possible to determine the cause of the decimal place shifting its position, there remains the issue of animate nominal subject [4]. This shows that natural language examples are not easily manipulate-able.

\subsubsection{Passive Verbal Groups Are Invariably Intransitive}

Passives are a subclass of intransitive verbal group clauses [10] because, like intransitives, they lack complements [17] and generally occur with or without adjuncts. Passive intransitive clauses with adjuncts are illustrated as follows.
$\mathrm{S} \quad \mathrm{P}$

(5ai) RK83|| They | must be filled (111) | of the Holy Spirit.||

$$
\begin{array}{llll}
\mathrm{A}_{1} & \mathrm{~S} & \mathrm{P} & \mathrm{A}_{2}
\end{array}
$$

(5aii) GK194|| After some time | the marriage | is blessed (220) | with children.||

$$
\mathrm{S} \quad \mathrm{P} \quad \mathrm{A}
$$

(5aiii) PK29 ||The equation that combines these two | is known (38)| as Coulombs law.||

$$
\mathrm{S} \quad \mathrm{P} \quad \mathrm{A}
$$

(5aiv) CK162 || It | is not bonded (187) | strongly.||

Now, compare their adjunctless counterparts below.

(5bi) RK149 ||And | many of them | got converted(192). $\|$

$$
\mathrm{S} P
$$

(5bii) GK281 || There | are | lots of materials that have been gathered (325).||
A
$\mathrm{S}$
$\mathrm{P}$

(5biii) PK227 || The moment you start solving | the sign | has to be ignored (245).||

$$
\mathrm{S} \text { P- A -P }
$$

(5biv) CK160 || It | is | loosely | attached (185).||

There were nevertheless active intransitive clauses with $((5 \mathrm{ci})-(5 \mathrm{cii}))$ and without $((5 \mathrm{cii})-(5 \mathrm{civ}))$ adjuncts, just as there 
were passive transitive clauses $((5 \mathrm{~d}))$. In other words, not all passives are intransitive and not all intransitive clauses are passives.
$\mathrm{S}$
$\mathrm{P}$
A

(5ci) RK219|| They | started ministering (278) | onto the people. $\|$

$\begin{array}{llll}\mathrm{A}_{1} & \mathrm{~S} & \mathrm{P} & \mathrm{A}_{2}\end{array}$

(5cii) CK374|| then | you | distil (408)| fractionally.||

$\mathrm{S} \quad \mathrm{P}$

(5ciii) GK518||The river | has rejuvenated (567).||

$$
\mathrm{S} \quad \mathrm{P}
$$

(5civ) PK313||This | will cancel out (348).||

$$
\mathrm{S} P \mathrm{C}
$$

(5d) RK222||We | were told (283) | [ [ that it can come to the lives of a person in different

$$
\text { ways]].||K223 || Were | you | taught (285) | that ?\| }
$$

\subsubsection{Passivisation Is Possible Only with Transitive Verbal Groups}

The assertion that passivisation as an underlying transformational process is possible only with active transitive verbal groups stems from the general rule that passives derive from the active transitive and that only transitive verbal groups occur with nominal complements[9]. The data has proofs of this, as illustrated below.

(6ai) RK214|| But $\mid$ they | needed (272) | something extra.||(AT)

$$
\mathrm{A} \quad \ell \mathrm{S} \quad \mathrm{P} \quad \mathrm{C}
$$

(6aii) GK53|| So | when | I | asked (56) | that question, ||(AT)

$$
\mathrm{S} P \mathrm{C} \quad \mathrm{A}
$$

(6aiii) PK128|| You | can use (147) | indices | [[to solve this]].||(AT)

$$
\mathrm{S} \quad \mathrm{P}
$$

(6aiv) CK510a || $\mathrm{We} \mid$ do not manufacture (553) | most of the things we use.||(AT)

That (6bi) - (6biv) are passivisable is demonstrated by the following analysed clauses.

$$
\mathrm{S} \quad \mathrm{P} \quad \mathrm{A}
$$

(6bi) || Something extra | is needed | (by them). $\|$ (PI)

$$
\begin{array}{lllll}
\mathrm{A}_{1} & \ell & \mathrm{S} & \mathrm{P} & \mathrm{A}_{2}
\end{array}
$$

(6bii) $\|$ So $\mid$ when | that question | was asked | (by me). $\|(\mathrm{PI})$

$$
\begin{array}{llll}
\mathrm{S} & \mathrm{P} & \mathrm{A}_{1} & \mathrm{~A}_{2}
\end{array}
$$

(6biii) || Indices | can be used | (by you) | [[to solve this]].||(PI)

$$
\mathrm{S} \quad \mathrm{P} \quad \mathrm{A}
$$

(6biv) ||Most of the things we use | are not manufactured | (by us).||(PI)

Compare (6biii) with (6bv) below. Notice the difference in meaning.

$$
\begin{array}{llll}
\mathrm{S} & \mathrm{P} & \mathrm{A}_{1} & \mathrm{~A}_{2}
\end{array}
$$

(6bv) || This | can be solved | (by you) | [[ using indices]].||

While it was possible to passivise (6ai) - (6aiv), the same grammatical operation cannot be achieved with (6ci) and (6di) below because the nominal groups are functionally adjuncts. So, though the occurrence of a nominal group complement is a condition for passivisation, not every nominal group is admissible as subject of passives. As shown below, "some passives automatically derived by rule from actives are" indeed "grotesque curiosities" [8].

$$
\begin{array}{lllll}
\mathrm{A}_{1} & \mathrm{~S} & \mathrm{~A}_{2} & \mathrm{P} & \mathrm{A}_{3}
\end{array}
$$

(6ci) GK297|| Then | the water| now | is flowing (340) |that way.||

$$
\begin{array}{llll}
\mathrm{A}_{1} & \mathrm{P} & \mathrm{A}_{2} & \mathrm{~A}_{3}
\end{array}
$$

(6cii) * ||That way | is being flowed | by the water | now. $\|$

$$
\mathrm{S} \quad \mathrm{P} \quad \mathrm{A}
$$

(6di) PK671||The positive | will be moving (742) | this way.||

$$
\begin{array}{lll}
\mathrm{A}_{1} & \mathrm{P} & \mathrm{A}_{2}
\end{array}
$$

(6dii) *||This way | will be being moved | by the positive.||

Finally, intransitive verbal group clauses are not passivisable.
$\mathrm{S}$
$\mathrm{P}$
$\mathrm{P}$
A

(6e) RK171|| Somebody else | should read (221).|| *|| Should be read | by somebody else.|| 


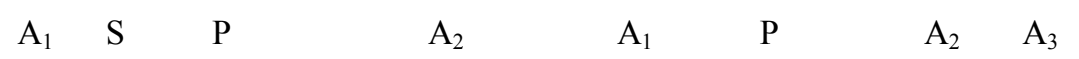

(6f) GK494|| then | you | behave (548) | maturely.|| *|| Maturely | is behaved | by you | then. ||

\subsubsection{Some Ditransitive Verbal Group Clauses Yield Dual Passive Constructions}

Reference [3] observes that some active ditransitive verbal group clauses yield dual passive analogues. One example is analysed with its passive analogues thus:

$$
\begin{array}{llll}
\mathrm{S} & \mathrm{P} & \mathrm{C}_{1} & \mathrm{C}_{2}
\end{array}
$$

(7ai) PK572|| You | are giving (632) | me | the distance apart.||

$$
\mathrm{S} \quad \mathrm{P} \quad \mathrm{C} \quad \mathrm{A}
$$

(7aii) || I | am being given | the distance apart |(by you ).||

$$
\mathrm{S} \quad \mathrm{P} \quad \mathrm{C} \quad \mathrm{A}
$$

(7aiii) ||The distance apart | is being given |(to) me | (by you).||

Notice that both the active transitive and its constructed passive analogues express the same meaning. But it is not so with (7bi) below, where there is no voice neutrality.

$$
\begin{aligned}
& \begin{array}{llll}
\mathrm{S} & \mathrm{P} & \mathrm{C}_{1} & \mathrm{C}_{2}
\end{array} \\
& \text { (7bi) CK676 || It | will give (725) | you | copper two oxide.|| } \\
& \mathrm{S} \quad \mathrm{P} \quad \mathrm{C} \quad \mathrm{A} \\
& \begin{array}{llll}
\mathrm{S} & \mathrm{P} & \mathrm{C} & \mathrm{A}
\end{array}
\end{aligned}
$$

The meaning indicated by the passive analogues can be paraphrased as "something will reward you with copper two oxide", which contrasts sharply with that of the active transitive, paraphrase-able as "something will result in copper two oxide". The context supports this interpretation.

(7biv) CK643 Let us use copper.K643 So, because copper is cheap and K644 it is also reactive in the air, K645 it will serve our purpose...K655You place it in a furnace...

K669 You heat the copper and K670 pass air through it...

K672What does it take from the air? K673It takes oxygen from the air. K674 It will give you copper...K675Copper

$$
\begin{array}{llll}
\mathrm{S} & \mathrm{P} & \mathrm{C}_{1} & \mathrm{C}_{2}
\end{array}
$$

(7ci) GK527 || We | call (574) | this one | oxbow lake.||

$$
\mathrm{S} \quad \mathrm{P} \quad \mathrm{C} \quad \mathrm{A}
$$

(7cii) ||This one | is called | oxbow lake | (by us). ||

$$
\mathrm{S} \quad \mathrm{P} \quad \mathrm{C} \quad \mathrm{A}
$$

(7ciii) * ||Oxbow lake $\mid$ is called $\mid$ this one | (by us). $\|$

Notice that though (7civ) below expresses the same meaning as $(7 \mathrm{ci})$, the former does not syntactically derive from the latter.

$$
\mathrm{S} \quad \mathrm{P} \quad \mathrm{C}
$$

(7civ)? || Oxbow lake | is | [[what this one is called (by us) ]].\|

Another ditransitive clause exhibiting features similar to (7ci) above is analysed below.

$$
\begin{array}{llll}
\mathrm{S} & \mathrm{P} & \mathrm{C}_{1} & \mathrm{C}_{2}
\end{array}
$$

(7di) CK75|| We | call (93) | them | lone pair.||

$$
\begin{array}{llll}
\mathrm{S} & \mathrm{P} & \mathrm{C} & \mathrm{A}
\end{array}
$$

(7dii) ||They | are called | lone pair | (by us). $\|$

$$
\mathrm{S} \quad \mathrm{P} \quad \mathrm{C} \quad \mathrm{A}
$$

(7diii) * || Lone pair | is called | them | (by us). $\|$

Notice however that (7div) below semantically corresponds with (7di) above.

$$
\mathrm{S} \quad \mathrm{P} \quad \mathrm{C}
$$

(7div) ||Lone pair | is | [[what they are called (by us) ]]. .|

Dual passive analogue is equally not possible with the rankshifted clause as second complement. Thus an attempt to transform [[what fractional distillation is]] in (7ei) to subject yields the grammatically unacceptable passive clause analysed as (7eiii) below. two oxide, $2 \mathrm{CuO}$....K676 It will give you copper two oxide. The foregoing shows that the passive constructions of some ditransitive clauses may be grammatically acceptable but semantically inappropriate.

There appears to be some difficulty with the second nominal group in the passivisation process. In comparison with the active transitive (7cii) below is syntactically awkward and semantically incongruous. This is a further proof that not all active ditransitive verbal group clauses can yield dual passive constructions that are syntactically acceptable and voice neutral. 
$\mathrm{P}-\quad \mathrm{S} \quad-\mathrm{P} \quad \mathrm{C}_{1} \quad \mathrm{C}_{2}$

(7ei) CK386 || Can | somebody | tell (420) | me | [[what fractional distillation is]]?||

$\mathrm{P}-\mathrm{S} \quad \mathrm{P} \quad \mathrm{C} \quad \mathrm{A}$

(7eii) || Can $|\mathrm{I}|$ be told $\mid[[$ what fractional distillation is]] | (by somebody)]]?||

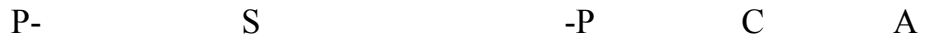

(7eiii) * $\|$ Can $\mid$ [[what fractional distillation is]] | be told $\mid$ (to) me | (by somebody)? $\|$

Because (7ei) is also an interrogative clause it should not be construed that active ditransitive clauses in interrogative mood cannot yield dual passive analogues. They can, as (7fi) - ( 7 fiii) confirm.

$$
\begin{array}{lllll}
\mathrm{P}- & \mathrm{S} & -\mathrm{P} & \mathrm{C}_{1} & \mathrm{C}_{2}
\end{array}
$$

(7fi) CK771 || Can | somebody | give (815) | me | a strong alkaline?||
$\mathrm{P}-\mathrm{S} \quad-\mathrm{P}$
$\mathrm{C}_{1}$
A

(7fii) $\|$ Can $|\mathrm{I}|$ be given $\mid$ a strong alkaline | (by somebody)? $\|$
$\mathrm{P}$ -
$\mathrm{S}$
$-\mathrm{P}$
$\mathrm{C}$
A

(7fiii) $\|$ Can | a strong alkaline | be given | (to) me | (by somebody)? ||

The absence of a grammatical subject excludes imperative clauses from a consideration of transitivity and voice. Thus (7gi) and (7gii) below cannot be active transitive because nothing seems to be extending from any entity to some other.

$$
\text { P- } \mathrm{C}_{1}-\mathrm{P} \quad \mathrm{C}_{2} \quad+\quad \mathrm{P}
$$

(7gi) PK342||| Let | me | use (373)| another calculator $\|$ and K343 || check.|||

$$
\mathrm{P} \quad \mathrm{C}_{1} \quad \mathrm{C}_{2}
$$

(7gii) PK344|| Give (375) | me | a good one.||

Notwithstanding the above fact, (7gii) is "passivisble" if the theoretically understood subject (contextually you) is invoked and if the semantic connection between imperatives expressing "command" and modals expressing "obligation" is explored[5]. Its most likely passive transforms are:

$$
\begin{gathered}
\text { S } \\
\begin{array}{c}
\text { (7giii) } \| \mathrm{I} \mid \text { should be given } \mid \text { a good one } \mid \text { (by you). } \| \\
\text { S }
\end{array} \quad \mathrm{P} \\
\text { (7giv) } \| \text { A good one | should be given | (to) me (by you). } \|
\end{gathered}
$$

Excerpt (7gv) below illustrates this semantic connection more succinctly: Ignore the lexical slip, and it cannot but be clear that the imperative clause restates the meaning conveyed by the declarative.

(7gv) CK463 Somebody should tell (505) me a noble gas and what we use it for. K465 Give me an example of

$$
\begin{gathered}
\mathrm{S} \\
\text { (7gvi) }|| \mathrm{I} \mid \text { should be "given" | an example of a noble gas | (by somebody). } \| \\
\mathrm{S}
\end{gathered}
$$

That PK344 Give me a good one and CK465 Give me an example of a noble gas are passivisable questions the traditional definition of transitivity and the continued insistence on a marked subject as a condition for transitive verb occurrence and, therefore, passivisability. Or could their passivisation have been possible because of the understood subjects you and somebody? But passive imperatives are not

unknown in English (See [3], [8] and 18]); they only lack active counterparts, as "Don't be intimidated" attests [2].

The catenated ditransitive verbal group poses its peculiar problems as a syntactically complex structure. As the passive analogues of (7hi) below show, where passivisation is syntactically possible, with catenation intact, there is an obvious lack of voice neutrality, for instance.

(7hi) RK245 || He | wanted to give (316) | them | money.||(AT)

$$
\mathrm{S} \quad \mathrm{P} \quad \mathrm{C} \quad \mathrm{A}
$$

(7hii) || $\mathrm{He} \mid$ wanted $\mid$ them $\mid[[$ to be given money]].||(AT) (No voice neutrality, no catenation)

$$
\mathrm{S} \quad \mathrm{P} \quad \mathrm{C}
$$

(7hiii) || They | wanted to be given | money.||(PT) (Catenation without voice neutrality)

$$
\mathrm{S} \quad \mathrm{P} \quad \mathrm{C} \quad \mathrm{A}
$$

(7hiv) || $\mathrm{He} \mid$ wanted $\mid$ money |[[ to be given (to) them]].|| (Voice neutrality without catenation) 


\subsubsection{Particled 1diomatic Verbal Groups must be Followed by their Nominal Complements, if Active}

Ordinarily particled idiomatic verbal groups used transitively are followed immediately by their nominal complements. With passivisation, however, the particle is moved to the final position in the new intransitive construction[19]. Particled passives were quite rare, and none had the complex preposition[20]. The closest that matches this description are shown as follows.

(8ai) CK596 By the time you have sodium K597 you

$$
\mathrm{S} \quad \mathrm{P} \quad \mathrm{C}
$$

(8bi) ||Sodium | will take up | the oxygen.||

$$
\mathrm{S} \quad \mathrm{P} \quad \mathrm{C} \quad \mathrm{A}_{1} \quad \mathrm{~A}_{2}
$$

(8bii) RK605||The Holy Spirit ... (K606) took (761) | him | away | from there.||

\subsubsection{Both Transitive and Active Voice Verbs Occur with Animate Nominal Group Subjects}

Whereas active transitive verbs generally tend to occur with animate nominal groups as subjects [4], the subjects of the passive "have a tendency towards inanimateness" [8]. The data analysed confirms this: Eighty-one per cent (638) of expose sodium to oxygen, K598 what will it form?... K602 It will form sodium oxide... K606 The oxygen will be taken up (663) by who?...K608 Sodium.

(8aii) RK604 and what were we told happened to Philip?

(R: He was taken away by the Holy Spirit.) K605 The

Holy Spirit caught him up again and K606 took him away from there.

Now compare the recoverable active transitive counterparts analysed below.

$$
\begin{array}{llllllll}
\mathrm{P}- & \mathrm{S} & -\mathrm{P} & \mathrm{C} & \mathrm{S} & \mathrm{P} & \mathrm{C}
\end{array}
$$

(9ai) RK567 || Did | Jesus | open (706)| his mouth? || K568 || He | didn't say (707)| anything.||

(9aii) PK406 Since the charges, K407 the values of the charges are not yet given,

$$
\mathrm{S} \quad \mathrm{P} \text { C }
$$

K408 || q | should cancel out (434) |q.. $\mid$

The following excerpts illustrate passive intransitive with animate and inanimate subjects respectively.

$$
\mathrm{S} \quad \mathrm{P}-\mathrm{A}_{1} \quad-\mathrm{P} \quad \mathrm{A}_{2}
$$

(9bi) RK237 ||The people| were | evenly| baptised (303) | in the Holy Spirit.||...
$\mathrm{A}_{1} \mathrm{~S}$
$\mathrm{P}$
$\mathrm{A}_{2}$

K264 || So | he| was told to perish (242) |with his money.||
$\mathrm{S}$
$\mathrm{P}$
$\mathrm{A}_{1}$
$\mathrm{A}_{2}$

(9bii) GK602|| The Kainji Dam $\mid$ is found (651) | at the middle of the river $\mid[$ [ where the river

$$
\mathrm{S} \quad \mathrm{P}
$$

has collected many tributaries]].||..K606 || Aswan Dam | is constructed (654) | after the White and the Black Nile.||

All the ten passive transitive clauses however had animate subjects.

(9ci) RK602 And immediately they came down from the chariot and K603 Philip baptised him.

$$
+ \text { C- P- S -P } \quad-C
$$

K604|| And | what | were | we | told (758) | happened to Philip?||

The un-inverted clause analysed below clearly identifies we as the animate subject.

$$
\mathrm{S} \quad \mathrm{P} \quad \mathrm{C}
$$

(9cii) || We | were told | [[something happened to Philip]].||

The active intransitive verbal group clauses occurred less with animate, than with inanimate, nominal group subjects. These are illustrated respectively as follows.

$$
\begin{array}{llll}
\mathrm{S} & \mathrm{P} & \mathrm{A}_{1} & \mathrm{~A}_{2}
\end{array}
$$

(9di) CK189 || Nitrogen | occurs (212) | abundantly | in the air atmosphere.||

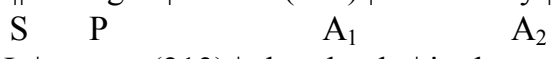

K190|| It | occurs (213) | abundantly | in the atmosphere.||

(9dii) PK329 I have thirty two. K330 You have twenty nine. K331 So is the calculator wrong?

$$
\text { K332|| You | are laughing (365).॥ }
$$

The occurrence of animate and inanimate nominal group subjects was found to be text-related: For instance, passive intransitive verbal group clauses with animate nominal group subjects were virtually restricted to the Christian Religious Knowledge text ( 9 out of 10), where persons and personalities formed an integral part of the topic taught. 


\subsubsection{Not all Active Transitive Clauses Have Passive Counterparts}

Though passives derive from active transitive verbal group clauses, not all active transitive have passive analogues [21]. This is characteristic of stative verbs, exemplified by HAVE below.

(10a) RK145 So the people had (188) no option.

*No option was had by the people.

(10b) GK198b You have (225) your own children too.

*Your own children are had by you too.

[10c] PK279 It has (312) magnitude and direction. *Magnitude and direction are had by it.

(10d) CK15 Nitrogen has (19) an atomic number. *An atomic number is had by nitrogen.

\subsubsection{Transitive Verbs with Rankshifted Clauses as} Complements Are Passivisable Only by Extraposition

According to [3], transitive verbs with the rankshifted clause as complement can only be transformed into the passive by extraposition and replacement with the pronoun it.
Thus RK95 || I | hope (125)| [| you have your Bibles]].|| and PK349 || I | think (164) | [|that we have discovered the mistake]l. || cannot be passivised as

(11a) *\|[ [ That you have your Bibles]]| is hoped $\mid$ (by me).\|

and

(11b) * ||[[That we have discovered the mistake $]]$ is thought | (by me).|l,

but as

(11c) || It | is hoped | [[ that you have your Bibles]].|| and

(11d) || It | is thought $\mid$ [[ that we have discovered the mistake]].\|,

respectively.

It does seem however that the transposition and replacement condition is restricted and does not apply in all cases. It is not possible with (11ei) below, for instance, even though the rankshifted clause at $\mathrm{C}$ is a finite one; rather, a more acceptable passive transform is (11eiii). Compare both:

A S $\mathrm{P}$

$\mathrm{C}$

(11ei) PK651|| So | the diagram | determines(724)|[[ how you get the electric field intensity]].||

$$
\mathrm{S} \quad \mathrm{P} \quad \mathrm{C} \quad \mathrm{A}
$$

(11 eii) * || It | is determined | [[ how you get the electric field intensity]] | (by the diagram). $\|$

$$
\mathrm{S} \quad \mathrm{P} \quad \mathrm{A}
$$

(11eiii) ||[[ How you get the electric field intensity] $\mid$ is determined | (by the diagram). $\|$

\subsubsection{Some Verbs Occur Only as Passives and Therefore cannot Be Active or Transitive}

Not only do verbs that occur exclusively as passives not function as active as well, they cannot be used transitively too [3]. The only such verb restricted to the passive in the data is born, and its incongruence as active transitive is illustrated below.

$$
\begin{aligned}
& \begin{array}{llllll}
\mathrm{A}_{1} & \mathrm{~S} & \mathrm{P}-\mathrm{A}_{2} & -\mathrm{P} & \mathrm{A}_{3}
\end{array} \\
& \text { (12a) GK515 || Yes | the river | is | now | born (563) | again. || } \\
& \begin{array}{llll}
\mathrm{S} & \mathrm{P} & \mathrm{C} & \mathrm{A}
\end{array} \\
& \text { (12b) * || The river| bore | itself |again.|| }
\end{aligned}
$$

\subsubsection{Transitivity Selects Finite Only, but the Passive can Be both Finite and Non-finite}

By virtue of its point of origination being the "major" clause [6], transitivity is said to select only finite from the system of finiteness. Thus gaveG466) and were able to satisfy G469 in (13ai) below are intransitive because they are finite, whereas sayingG470 is not functioning transitively despite its nominal complements because it is non-finite.

(13a) GK418 When I gave (466) that question to that class...K420 only two students were able to satisfy (469)

me, K421 saying (470) that the place is liable to flooding.

Similarly whereas had to giveR25 in (13aii) is transitive, to bringR19 is neither transitive nor intransitive because it is non-finite.

(13aii) RK16 From your own background knowledge what is the mission of the Church?...K16 To bring (19) the lost souls back to Christ...K21 Because, before he left, K22 he had to give (25) them this commission to do something.

In contrast, verbal groups marked for passive voice select both finite and non-finite from the system of finiteness (See [3] for the non-finite passives "to be examined" and "[being] examined"). Although [8]'s list of "verbal group types and some of their combinations" excludes the non-finite passive, (13bi) and (13bii) provide evidence that they were accounted for.

(13bi) "If / "wè had been offered the choice of being killed or not that móment \#" (p83)

(13bii) "The person convicted was fined only a pound" (p134)

Our data reflects both finite and non-finite passive verbal groups, as (13c) shows.

(13c) RK353 You could see healing taking place... and

K355 demons being cast out (460) of the people...K360

Apart from healing the sick demons were cast out (463).

The morphologically invariant $\mathrm{x}+\mathrm{n}$ mathematics passives dominated the non-finite passive.

(13d) PK575 What is the value of negative q? K576 Five point zero times ten raised (636) to power minus eight all over o point five bracket squared (653). K577 Any question? K578 divided (639) by hundred o point o five.

\subsubsection{The Transitive and Intransitive Occur Only as Predicators, but the Passive Is Unrestricted}


Only verbal groups functioning at the primary degree of delicacy as predicators are considered for their transitivity roles [6]. This makes has not collected (170) in (14a) below intransitive, and will makeG171 and widenG172, which function within the structure of a rankshifted clause at $\mathrm{A}$, neither transitive nor intransitive.

$\mathrm{S}$

(14b) GK147 || It | has not collected (170) | enough river or enough water | from the tributaries

$\mathrm{A}_{2}$

distributaries |[[ that will make (171) it widen (172) ]]. \|

In contrast, passives additionally function at the most delicate level syntactically as already seen. Excerpt (14c) below illustrates passives functioning at the tertiary, secondary and primary degrees of delicacy respectively.

$$
\mathrm{S} \quad \mathrm{P} \quad \mathrm{A}
$$

(14c) PK6 || An electric force | exist(s)| around any body [[ that is charged (8)]]. .|..

$$
\mathrm{S} \mathrm{P} \quad \mathrm{C}+\mathrm{S}-\quad \mathrm{A}_{1}
$$

K79|| That | is |[[where you got confused (103)]].||..K101 || But |everything | altogether|

$$
-\mathrm{S} \quad \mathrm{P} \quad \mathrm{A}_{2}
$$

$[[$ divided by one]] $\mid$ is given (123) $\mid$ as nine times ten raised to power nine. $\|$

\section{Conclusions}

This study has demonstrated that, beside belonging to both the verbal group and clause systems, transitivity and voice are syntactically related. It has presented a holistic description of the syntactic relationship between transitivity and voice by analysing 2,187 FVBG clauses to determine their transitivity and voice status and by ascertaining their occurrence in the data fourteen features of syntactic relationship between transitivity and voice identified in the literature. This concluding section highlights and discusses the findings.

The same FVBG clauses that indicated transitivity also displayed voice. However, the unmarked active voice was 26 per cent more frequent than the unmarked transitive, which suggests that voice is a more basic system to the FVBG clause than transitivity: Unmarked terms (kernel forms) are "syntactically more basic" than marked terms [2]. Voice manifestation was 91 per cent active and 9 per cent passive, which makes active voice the dominant term. The active transitive was similarly dominant over the active intransitive, accounting for 73 per cent. Passive voice was 91 per cent intransitive and 9 per cent transitive. In contrast, transitivity revealed as 67 per cent transitive and 33 per cent intransitive, which means that the transitive verbal group clause was twice as frequent as the intransitive. Monotransitivity was dominant; only 8 per cent of transitive verbal group clauses was ditransitive and none was passive, attesting to the infrequency of the passive ditransitive [8].The intransitive verbal group clause was 41 per cent adjuntless, with 25 per cent of it passive and 75 per cent active. Thus transitivity and voice featured as 65 per cent active transitive, 25 per cent active intransitive, 8.1 per cent passive intransitive, and 1 per cent passive transitive.

Whereas the subject of the passive transitive was all animate and that of the active transitive 81 per cent animate, 90 per cent of the passive intransitive had inanimate nominal group subjects. The nature of the texts analysed probably dictated this: Nine of the ten passive intransitive clauses with animate nominal group subjects occurred in the only text where persons and personalities featured as an integral part of the subject matter. The nominal group accounted for 83 per cent of complements and only 2 per cent of adjuncts; and, while the prepositional group represents 67 per cent of adjuncts and the adverbial 31 per cent, the rankshifted clause featured only as complements (17 per cent). The dominant complement and most recurring adjunct were therefore the nominal group and prepositional group respectively.

All fourteen features of syntactic relationship between transitivity and voice identified in the literature were reflected in the data. For instance, the general rule that transitive verbal groups are either active or passive was confirmed. On the assertion that passive clauses derive from active transitive ones however, only rarely did there occur such perfect correspondences of active transitive with passive transitive, or active transitive with passive intransitive, FVBG clauses. This can be explained by the fact that because the data is corpus-based, many passive clauses occurred naturally and without their active transitive counterparts, and vice versa (It was possible to reconstruct their active transitive, or passive transitive/intransitive, analogues from context, though). Moreover the passives generally functioned at the most delicate syntactic level, and many occurred without the auxiliary BE passive marker due to the dynamics of natural language. These set of passives are usually not accounted for in the grammar.

Also confirmed by the analysis is the notion that transitivity and voice both involve other elements of the clause structure. It was however demonstrated that not all nominal groups can be the subject of passive constructions and not all active ditransitive clauses can yield two grammatically appropriate passive constructions. The second nominal complement proved problematic, particularly that realised by the rankshifted clause. The transposition and replacement condition for passivisation of active transitive verbal groups with the rankshifted clause as complement was found inapplicable in some cases: A grammatically acceptable and semantically adequate passive analogue was constructed without resort to the pronoun it. Where the verbal group was catenated, none of the three constructible passive 
analogues was both syntactically acceptable and semantically appropriate. The only passive analogue retaining the same grammatical structure as the catenative in the active transitive did not express the same meaning. Catenation was moreover lost in two, with the same meaning retained in one, and a different meaning indicated in another. It was also demonstrated that the non-let imperative clause manifesting nominal complements was passivisable, which calls to question the insistence on the presence of the subject as a condition for transitivity and voice.

This analysis has thus shown that transitive verbal group clauses are predominantly active verbal group clauses and that, while intransitive verbal group clauses occur far more as active than passive, passive voice clauses are essentially intransitive. Furthermore, although passives are a subclass of the intransitive, not all passives are intransitive and not all transitive clauses are passive clauses as well. In essence, it has demonstrated that transitivity and voice share a lot in common and that there are differences too. To adequately account for both systems and their shared relationship, the finite verbal group clause should be taken as transitivity's point of origination. Regarding the "major" clause as its point of origination shuts out a significant proportion of data, as this study has revealed.

\section{References}

[1] C.J. Hall, An Introduction to Language and Linguistics, London: Continuum, 2005.

[2] R. Huddleston, Introduction to the Grammar of English, Cambridge: Cambridge University Press, 1984.

[3] R. Quirk, S. Greenbaum, G. Leech and J. Svartvik, A Comprehensive Grammar of the English Language, London: Longman, 1985.

[4] J. Lyons, An Introduction to Theoretical Linguistics, Cambridge: Cambridge University Press, 1968.

[5] M.A.K. Halliday and C. M.I.M. Matthiessen, Introduction to Functional Grammar, 3rd ed., London: Hodder Arnold, 2004.

[6] M.A.K. Halliday, "Notes on Transitivity and Theme in
English", Parts 1-3, Journal of Linguistics 3, 1967-8, pp 3781 .

[7] M.A.K. Halliday, "Types of Process", in G. Kress, ed., Halliday: System and Function in Language, Oxford: Oxford University Press, 1976, pp159-73.

[8] J. Svartvik, On Voice in the English Verb, The Hague: Mouton, 1966.

[9] F.R. Palmer, The English Verb, 2nd ed., London: Longman, 1987.

[10] A. Radford, English Syntax: An Introduction, Cambridge: Cambridge University Press, 2004.

[11] M.H. Klaiman, Grammatical Voice, Cambridge: Cambridge University Press, 1991.

[12] P. Simpson, "Transitivity as Point of View", Reprinted in L. Mullany and P. Stockwell, Introducing English Language: A Resource Book for Students, London: Routledge, 2010, pp257-264.

[13] R.A. Adejare, The English Verbal Group: Its Form, Meaning and Function, Saarbrücken: LAP LAMBERT Academic Publishing, 2013.

[14] M.A.K. Halliday, "Categories of the Theory of Grammar", WORD, vol.17, no 3, 1961, pp 241-92 (Rpt. as Bobbs-Merill Series, No Language 36).

[15] M. Tallerman, Understanding Syntax, 2nd ed., London: Hodder Education, 2005.

[16] P. Christophersen and A. O. Sandved, An Advanced English Grammar, London: Macmillan, 1969

[17] A. Downing and P. Locke, English Grammar, London: Routledge, 2006.

[18] S. Greenbaum and G. Nelson, An Introduction to English Grammar, 2nd ed., London: Longman, 2002.

[19] B.M.H. Strang, Modern English Structure, London: Edward Arnold, 1969.

[20] H. Hirao, "Up above as a Complex Preposition", English Linguistics Research, vol. 3, no.1, 2014,pp12-17.

[21] G. Nelson, English: An Essential Grammar, London: Routledge, 2001. 